\title{
Crop biomass and root morphology in maize/soybean strip intercropping system in karst region
}

\author{
Hao Zhang ${ }^{1,2,3, a}$, Fuping Zeng ${ }^{2,3, b}$, Qiujin $\operatorname{Tan}^{4, c}$, Guanghua $X^{2,3, d}$ \\ and Youzhi $\mathrm{Li}^{1, \mathrm{e}^{*}}$
}

\author{
${ }^{1}$ State Key Laboratory for Conservation and Utilization of Subtropical Agro-bioresources, Guangxi \\ University, Nanning, 530004, China \\ ${ }^{2}$ Key Laboratory of Agro-Ecological Processes in Subtropical Region, Institute of Subtropical \\ Agriculture, Chinese Academy of Sciences, Changsha, 410125 , China \\ ${ }^{3}$ Huanjiang Observation and Research Station for Karst Ecosystem, Chinese Academy of Sciences, \\ Huanjiang, 547100, China \\ ${ }^{4}$ South Asian Tropical Agricultural Science Research Institute of Guangxi, Longzhou, Guangxi \\ Zhuang Autonomous Region 532415, China \\ azhanghao@isa.ac.cn, bfpzeng@isa.ac.cn, ${ }^{\mathrm{c}}$ qiujinT110@163.com, ${ }^{\mathrm{d} x u g u a n g h u a @ i s a . a c . c n}$ \\ $\mathrm{e}^{*}$ dyzl@gxu.edu.cn (corresponding author)
}

Keywords: karst soil, maize/soybean, nutrient use, root morphology, strip intercropping system Abstract. It is still unclear that whether intercropping system (IS) could improve the crop biomass and yield in karst soil. A field experiment was conducted to analyze the effects of IS on maize/soybean biomass, root morphology and yield. The results showed that the maize aboveground biomass, root biomass, and yield in IS were significantly higher than those of maize sole cropping (MS). Similarly, the maize root length, root volume weight, and root actively in IS were significantly higher than these of MS. These data implied that IS has obvious advantage of crop biomass and yield in karst region, which was mainly due to the differences of root morphology and root activity.

\section{Introduction}

Intercropping, as one of traditional agricultural practice, can not only improve grain yield through more efficient use of resources such as radiation, water, and nitrogen [1,2], but also increase soil fertility, prevent soil erosion, and reduce the occurrence of diseases, insects and weeds [3,4]. Thus, it has been regarded as an alternative practice for sustainable agriculture [5]. In maize/soybean intercropping system, maize is sown and space is left open between the maize strips to enable sowing of soybean [6]. Previous studies have investigated the nutrient uptake [7,8], root distribution $[9,10]$ and water-use efficiency $[11,12]$ of this planting pattern. However, these researches were mainly conducted in non-karst area. In Southwest China, the karst region covers $5.5 \times 10^{5} \mathrm{~km}^{2}$ and is considered fragile because of its unique geological setting, low environmental carrying capacity, and low tolerance of disturbance [13]. Maize/soybean intercropping system is now one of dominant planting patterns in this area [14]. Therefore, it is important for food security in this region to explore the root morphological basis for the observed yield advantage of this system. In this study, we analyzed change of ground and underground biomass for soybean and corn in karst field. Response of root morphology to strip intercropping was also studied, which would provide theoretical guidance on the best field configuration in this region.

\section{Material and methods}

Study sites. Field experiments were conducted in 2014 at the Huangjiang karst experimental station in the Hechi city, in northwest Guangxi Zhuang autonomous region, China $\left(24^{\circ} 44^{\prime}-25^{\circ} 33\right.$ 'N; 
$107^{\circ} 51^{\prime}-108^{\circ} 43^{\prime} \mathrm{E}$, altitude $\left.220 \mathrm{~m}\right)$. Based on long-term (1971- 2010) weather data from the site, the mean annual air temperature is $18.5^{\circ} \mathrm{C}$. Mean temperatures in January and July are $10.1^{\circ} \mathrm{C}$ and $28.0^{\circ} \mathrm{C}$, respectively. There are 290 frost free days and 1451 sunshine hours per year. The region is water-sufficient, with a mean annual precipitation of $1389 \mathrm{~mm}$ and a mean annual pan evaporation of $1571 \mathrm{~mm}$ [13]. The soil of the site has lime soil, with 30- $90 \mathrm{~cm}$ soil depth.

Experimental designs. The experiments comprised three planting patterns with soybean (Glycine max) and maize (Zea mays L.): soybean sole cropping (SS), maize sole cropping (MS), and one intercropping systems (IS). Sole soybean was planted at a density of 62,500 plants ha ${ }^{-1}$ and inter-row distance of $0.35 \mathrm{~m}$, and the maize sole-cropping system was planted with a density of 81,632 plants $\mathrm{ha}^{-1}$, inter-row distance of $0.40 \mathrm{~m}$ and intra-row distance of $0.30 \mathrm{~m}$. The intercropping patterns were characterized by the number of soybean and maize rows that a whole intercrop strip concluded. Wheat and maize were planted at the same density on their strips in intercropping systems as in their respective sole-cropping systems. The distance between the soybean and maize strips was $0.28 \mathrm{~m}$. Each strip was planted with six maize rows or three soybean rows. Maize was planted on 25 March and harvested on 15 July, and soybean was planted on 22 July and harvested on 21 September in 2014. The individual plot areas were $5.0 \times 10.0 \mathrm{~m}^{2}$ for sole crops and $5.0 \times 20.0 \mathrm{~m}^{2}$ for intercropping system. Soybean and maize were fertilized with 240 and $360 \mathrm{~kg} \mathrm{~N} \mathrm{ha}^{-1}$, respectively.

Field sampling and measurements. Soybeans samples were collected in the third instars stage (V3), the fifth instars stage (V5) and full bloom stage (F2), respectively. Maize samples were collected in tasseling stage, milk stage and mature stage. The fresh aboveground biomass of maize and soybean were put into kraft paper bags, and oven-dried at $105^{\circ} \mathrm{C}$ for $30 \mathrm{~min}$ and then at $85^{\circ} \mathrm{C}$ until constant weights. In addition, the yields were computed by total corn grain and plants numbers.

The root morphology and biomass of maize and soybean were measure by using the traditional mining method [15]. In detail, the mixture of soil and roots around maize centre were dug according to the distribution characteristics of root system in maize and soybean, and washed by using 60 mesh griddles. Then, the clean root were scanned by root scanning image analysis system (WinRHIZO) and the root length, root volume were calculated [16]. The roots were oven-dried at $105^{\circ} \mathrm{C}$ for $30 \mathrm{~min}$ and then at $85^{\circ} \mathrm{C}$ until constant weights. Finally, the root actively was also measured by the method of TTC triphenyl four nitrogen chloride [17].

Data analysis. Statistical analyses were performed using SPSS 13.0 for windows (SPSS Inc., Chicago. IL).

\section{Results and Discussion}

Table 1 showed aboveground and root biomass in maize and soybean increased with increasing of life stage. The maize above and root biomass in intercropping system (IS) were significantly higher than those of maize sole cropping (MS). Compared for maize biomass, the soybean above and root biomass in IS were not significantly higher than those of soybean sole cropping (SS). Similarly, the maize yield in IS was significantly higher than that of MS. In a whole, these data indicated that the IS has obvious advantage of crop biomass and yield (Table 1).

Table 2 demonstrated that the maize root length, root volume weight, and root actively in IS were significantly higher than these of MS. On the contrary, the soybean root length, root volume weight in IS were not significantly higher than these of SS. In addition, there were significantly difference between the soybean root actively in IS and SS. Thus, the difference of crop nutrient uptake was mainly due to the differences of root morphology and root activity.

In this study, our data clearly demonstrated that intercropping systems presented advantage over maize monoculture. Intercropping system of maize with legumes reduced nitrogen application in the karst area compared to maize monoculture, probably because of the enhanced biological nitrogen fixation by legumes [5]. Maize/soybean systems showed intercropping advantages in biomass, yield, and land utilization ratio, as well as better residual effect on the subsequent crop. Previous studies had also reported beneficial effects of intercropping systems on yield, economy and the environment 
$[5,18]$, which stresses the importance of using intercropping in sustainable agriculture to alleviate pressure in intensive farming systems with high inputs and outputs [19]. Soybean is more important than red bean in China, with more consumption and relying on import, and decreasing planting area year by year [20]. Therefore, considering maize intercropping with soybean as the best cropping system in summer in the present study is reasonable and necessary.

Table 1 Dry biomass (g/plant) and yield (kg/ha) of maize and soybean in different treats

\begin{tabular}{ccccc}
\hline Treats & Stages & Aboveground biomass & Roots biomass & Yield \\
\hline \multirow{2}{*}{ SS } & V3 & $3.93^{\mathrm{a}}$ & $0.05^{\mathrm{a}}$ & - \\
& V5 & $6.85^{\mathrm{a}}$ & $0.08^{\mathrm{a}}$ & - \\
& R2 & $27.31^{\mathrm{a}}$ & $2.31^{\mathrm{a}}$ & $980.5^{\mathrm{a}}$ \\
IS & V3 & $4.16^{\mathrm{a}}$ & $0.07^{\mathrm{a}}$ & - \\
(Soybean) & V5 & $7.52^{\mathrm{a}}$ & $0.10^{\mathrm{b}}$ & - \\
& R2 & $31.47^{\mathrm{a}}$ & $2.47^{\mathrm{a}}$ & $1023.8^{\mathrm{a}}$ \\
& V3 & $7.80^{\mathrm{b}}$ & $1.10^{\mathrm{b}}$ & - \\
MS & V5 & $71.65^{\mathrm{b}}$ & $4.22^{\mathrm{b}}$ & - \\
& R2 & $432.62^{\mathrm{b}}$ & $22.62^{\mathrm{b}}$ & $7089.4^{\mathrm{b}}$ \\
IS & V3 & $26.08^{\mathrm{c}}$ & $1.48^{\mathrm{c}}$ & - \\
(Maize) & V5 & $130.60^{\mathrm{c}}$ & $4.60^{\mathrm{c}}$ & - \\
& R2 & $591.33^{\mathrm{c}}$ & $31.33^{\mathrm{c}}$ & $9072.9^{\mathrm{c}}$ \\
\hline
\end{tabular}

Notes: Different letters for the same variable indicate a significant difference between the different forest ecosystems $(p<$ $0.05)$, the same as below.

Table 2 Root morphology and activity of maize and soybean in different treats

\begin{tabular}{ccccc}
\hline Treats & Stages & $\begin{array}{c}\text { Root length } \\
(\mathrm{cm} / \text { plant })\end{array}$ & $\begin{array}{c}\text { Roots volume } \\
\left(\mathrm{cm}^{3} / \text { plant }\right)\end{array}$ & $\begin{array}{c}\text { Root activity } \\
(\mu \mathrm{g} / \mathrm{g} / \mathrm{hr})\end{array}$ \\
\hline \multirow{2}{*}{ SS } & V3 & $68.62^{\mathrm{a}}$ & $2.96^{\mathrm{a}}$ & $9.58^{\mathrm{a}}$ \\
& V5 & $135.34^{\mathrm{a}}$ & $5.85^{\mathrm{a}}$ & $32.59^{\mathrm{b}}$ \\
& R2 & $256.71^{\mathrm{a}}$ & $10.08^{\mathrm{a}}$ & $8.16^{\mathrm{a}}$ \\
IS & V3 & $74.19^{\mathrm{a}}$ & $2.67^{\mathrm{a}}$ & $9.93^{\mathrm{a}}$ \\
(Soybean) & V5 & $127.51^{\mathrm{a}}$ & $7.01^{\mathrm{a}}$ & $40.85^{\mathrm{c}}$ \\
& R2 & $265.79^{\mathrm{a}}$ & $11.14^{\mathrm{a}}$ & $9.26^{\mathrm{b}}$ \\
& V3 & $197.61^{\mathrm{b}}$ & $9.29^{\mathrm{b}}$ & $12.37^{\mathrm{b}}$ \\
MS & V5 & $373.44^{\mathrm{b}}$ & $65.73^{\mathrm{b}}$ & $27.20^{\mathrm{a}}$ \\
& R2 & $549.70^{\mathrm{b}}$ & $141.16^{\mathrm{b}}$ & $8.96^{\mathrm{a}}$ \\
& V3 & $226.80^{\mathrm{c}}$ & $14.81^{\mathrm{c}}$ & $18.81^{\mathrm{c}}$ \\
IS & V5 & $478.69^{\mathrm{c}}$ & $79.09^{\mathrm{c}}$ & $33.48^{\mathrm{b}}$ \\
(Maize) & R2 & $638.32^{\mathrm{c}}$ & $162.32^{\mathrm{c}}$ & $9.79^{\mathrm{b}}$ \\
\hline
\end{tabular}

Advantage of intercropping may be probably derived from high light use efficiency above-ground and nitrogen nutrients below-ground $[9,21]$. Ability of maize to capture sunlight was enhanced at border rows, while there was small difference in photosynthetic rate and transpiration rate between inner-rows within a strip [21, 22]. In addition, intercropped soybean probably facilitated growth of maize by transferring the nitrogen fixed [23]. In this research, our data found that maize root length, root volume weight, and root actively in intercropping systems were significantly higher than these of maize sole cropping. However, more nitrogen fertilization would inhibit nitrogen fixation of legumes [24], thus nitrogen was applied as basal fertilizer to both maize and soybean but only top dressed for maize in this study. Other results also showed that intercropping could provide enough nitrate for crops during the whole growth period. Soil nitrate nitrogen in maize monoculture gradually increased to the highest value at ripening stage compared to intercropped maize, while soil nitrate nitrogen in soybean monoculture gradually decreased to the lowest value at ripening stage compared to intercropped soybean [25]. Finally, although our experiments tested the crop biomass and root 
morphology in maize/soybean intercropping system in karst soil, however, some other influencing factors (i.g. row spacing, crop variety, soil microbiology etc.) should be considered in the further research.

\section{Acknowledgements}

This research was supported by the State Key Laboratory for Conservation and Utilization of Subtropical Agro-bioresources (SKL201403); Guangxi Science and Technology Development Plan (GKG1598016-2); National Science and Technology Support Plan (2015BAD06B04); the " 100 talents program" of the Chinese Academy of Sciences (2060299, Y251101111); the Western Light Program of Talent Cultivation of the Chinese Academy of Sciences and Guangxi Provincial Program of Distinguished Expert in China.

\section{References}

[1] R. Willey, Intercropping: its importance and research needs: I. Competition and yield advantages, Field Crops Abstr. 32 (1979) 1-10.

[2] F. Zhang, J. Shen, L. Li, X. Liu, An overview of rhizosphere processes related with plant nutrition in major cropping systems in China, Plant Soil. 260 (2004) 8-99.

[3] R. W. Willey, Resource use in intercropping systems, Agric. Water Manag. 17 (1990) 215- 231.

[4] P.K.Ghosh, A.K.Tripathi, K. K Bandyopadhyay, M.C. Manna, Assessment of nutrient competition and nutrient requirement in soybean/sorghum intercropping system, Eur. J. Agron. 31 (2009) 43-50.

[5] K.X.Wu and B.Z.Wu, Potential environmental benefits of intercropping annual with leguminous perennial crops in Chinese agriculture, Agri. Ecosys. Environ. 188 (2014) 147-149.

[6] F.Yang, S.Huang, R.C. Gao, W.G. Liu, T. W.Yong, X. C. Wang, X. L.Wu, W. Y Yang, Growth of soybean seedlings in relay strip intercropping system in relation to light quantity and red:far-red ratio, Field Crops Res. 155 (2014) 245-253.

[7] T. D.Liu, F. B.Song, S. Q.Liu, X. C Zhu, Light interception and radiation use efficiency response to narrow-wide row planting patterns in maize, Aust. J. Crop. Sci. 6(2012) 506-513

[8] G.A.Maddonni, M. E.Otegui, Intra-specific competition in maize: early establishment of hierarchies among plants affects final kernel set, Field Crops Res. 85(2004) 85: 1-13

[9] K.X.Wu, M.A.Fullen, T.X.An, Z.W.Fan, F.Zhou, G.F.Xue, Above- and below-ground interspecific interaction in intercropped maize and potato: A field study using the 'target' technique, Field Crops Res. 139 (2012) 63-70.

[10] G.Corre-Hellou, J.Fustec and Y.Crozat, Interspecific competition for soil N and its interaction with N-2 fixation, leaf expansion and crop growth in pea-barley intercrops, Plant Soil. 282 (2006) 195-208.

[11] H.Du, K.L.Wang, W.X.Peng, F.P.Zeng, T.Q. Song, H. Zhang, S.Y.Lu, Spatial heterogeneity of soil mineral oxide components in depression between karst hills, Southwest China, Chin. Geo. Sci. 24(2014) 163-179.

[12] H.Du, W.X.Peng, T.Q.Song, F.P.Zeng, K.L.Wang, M.Song, H.Zhang, Spatial pattern of woody plants and their environmental interpretation in the karst forest of southwest China. Plant Biosys. 149(2015)121-130. 
[13] J. Jin, G. H,Wang, X. B.Liu, Y. H.Li, X. L.Chen, S. J. Herbert, Characteristics of root distribution at R5 stage in high yielding soybean in black soil, Chin. J. Oil. Crop. Sci. 29(2007) 266-271 (in Chinese)

[14] Z. X. Li, Y. Q.Chen, Q. C.Wang, K. C.Liu, W. S. Gao, P. Sui, Influence of planting density on root spatio-temporal distribution of different types of maize under high-yielding cultivation conditions, Acta Agron. Sin. 38(2012)1286-1294 (in Chinese)

[15] H.Zhang, T.Q. Song, K.L.Wang, H.Du, Y.M.Yue, G.X. Wang and F.P. Zeng, Biomass and carbon storage in an age-sequence of Cyclobalanopsis glauca plantations in southwest China. Eco Eng, 73 (2014) 184-191.

[16] Q.J.Tan, F.P.Zeng, H.S.Chen, Z.S.Qin, H.Du, W.L.Wang, H.Zhang, Spatial variability of soil nutrients in Juglans regia of different ages in depression between karst hills, southwest China. Adv. Eng. Res. 45(2015) (In press)

[17] S.D. Bao, Soil and agricultural chemistry analysis, Agriculture Press of China, Beijing, China 2000.

[18] A.Z.Qin, G.B.Huang, Q.Chai, A.Z.Yu and P.Huang, Grain yield and soil respiratory response to intercropping systems on arid land, Field Crops Res. 144 (2013) 1-10.

[19] G.G.Zhang, Z.B.Yang and S.T.Dong, Interspecific competitiveness affects the total biomass yield in an alfalfa and corn intercropping system, Field Crops Res. 124(2011) 66-73.

[20] W.Chen, M.A.Marchant and A. Muhammad, China's soybean product imports: an analysis of price effects using a production system approach, China Agri. Eco. Rev. 4 (2012) 499-513.

[21] R.W.Neugschwandtner and H.P. Kaul, Sowing ratio and N fertilization affect yield and yield components of oat and pea in intercrops, Field Crops Res. 155 (2014) 159-163.

[22] R.B.Prasad, and R.M. Brook, Effect of varying maize densities on intercropped maize and soybean in Nepal, Exp. Agri. 41 (2005) 365-382.

[23] L.Li, J.H.Sun, F.S.Zhang, X.L. Li, S.C.Yang and Z.Rengel, Intercropping alleviates the inhibitory effect of $\mathrm{N}$ fertilization on nodulation and symbiotic N-2 fixation of faba bean, Field Crops Res. 71(2001) 123-137.

[24] G. Bergkvist, M. Stenberg, J. Wetterlind, B. Bath and S. Elfstrand. Clover cover crops under-sown in winter wheat increase yield of subsequent spring barley-Effect of $\mathrm{N}$ dose and companion grass, Field Crops Res. 120(2011) 292-298.

[25] P. Ramesh, P.K. Ghosh, S. A. Ramana, Effects of nitrogen on dry matter accumulation and productivity of three cropping systems and residual effects on wheat in deep vertisols of central, India J. Agr. Crop Sci. 188 (2002) 81-85. 